\title{
Akut sinüzit atağında frontal sinüs ön duvarındaki defekte bağlı olarak gelișen periorbital selülit: Olgu sunumu
}

\author{
Periorbital cellulitis caused by defect in front wall of frontal sinus in acute \\ sinusitis attacks: A case report \\ İsa Özbay, Fatih Oğhan, Cüneyt Kucur, Onur Erdoğan*, Sinan Aksoy, Zuhal \\ Zeybek Sivas
}

Kulak Burun Boğaz Anabilim Dalı (Yrd. Doç. İ. Özbay, Doç. Dr. F. Oğhan, Yrd. Doç. C. Kucur, Dr. O. Erdoğan, Dr. S. Aksoy, Dr. Z. Z. Sivas), Dumlupınar Üniversitesi Tıp Fakültesi, TR-43000 Kütahya

\section{Özet}

Sinüzit olgularında antibiyoterapi yaygın olarak kullanılmasına rağmen hala bir takım komplikasyonlar görülebilmektedir. Periorbital selülit daha çok çocukluk döneminde ve etmoid sinüslerin enflamasyonu ile ortaya çıkan göz kapağında ödem, hiperemi ve oküler ağrının hakim olduğu fakat görmenin etkilenmediği, nadirende apsenin eşlik ettiği bir klinik durumdur. Bizim olgumuz erişkin erkek hasta idi ve frontal sinüsteki defektten kaynaklanan periorbital selüliti mevcuttu. Bu hali ile diğer olgulardan farklılık gösteriyordu. Anamnezinde üç y1l önce fonksiyonel endoskopik sinüs cerrahisi geçirdiğini belirten hastanın travma öyküsü bulunmuyordu. Hastamızda periorbital selilüte neden olan durumun akut sinüzit seyrinde frontal sinüs duvarındaki defekten meydana geldiği ve apse formasyonuna yol açtığını 'ince kesit tomografi' ile tespit edildi. Servise yatırılan hastaya, parenteral antibiyoterapi başlandı. Hastanın klinik tablosunun tedavinin 5 . gününde düzeldiği görüldü. Operasyona alınan hastaya yapılan frontoetmoidal medial orbitotomi (Lynch) insizyonu sonrası frontal sinüs ön duvarındaki defektinin yaklaşık 2-3 mm çapında olduğu görüldü ve bonecement ile onarıldı. Bu tür defektlerde, etiyopatogenezde mukopiyosel, travma vs. olabileceği gibi iatrojenik travmalar da olabilir. Bu olguda akut sinüzit atağında frontal sinüs ön duvarındaki defektten meydana gelen atipik bir periorbital selülit olgusunu literatür eşliğinde tartışarak sunuyoruz.

Anahtar sözcükler: Periorbital selülit; frontal sinüs defekti; akut sinüzit

\begin{abstract}
Despite the widespread use of antibiotics in cases of sinusitis, still some complications may occur. Periorbital cellulitis is a clinical condition that usually seen in childhood and inflammation occurs in ethmoid sinuses causing eyelid edema, hyperemia and ocular pain, but seeing is generally unaffected, and rarely it is accompanied by the abscess. Our case was adult male patient and periorbital cellulitis was present caused by a defect in the frontal sinus. This is the difference from other cases. Functional endoscopic sinus surgery was present at 3 years ago in history of the patient who had no history of trauma. It has been detected in 'thin-section CT that periorbital cellulites of our patient caused by the defect in the wall of the frontal sinus in the course of acute sinusitis and then, abscess formation occurred. Parenteral antibiotic therapy was given to the patient who was hospitalized. On the 5th day of treatment, the patient's clinical improvement was observed. Frontoetmoidal medial orbitotomy (Lynch) incision was made to the patient in operation and the defect was found to be approximately $2-3 \mathrm{~mm}$ in diameter in the anterior wall of the frontal sinus and it was repaired with bone cement. Ethiopathogenesis of this type of defect may be mukopiyosel, trauma etc. as well as iatrogenic trauma. In this case, we offer an atypical case of periorbital cellulitis caused by the defect in the anterior wall of the frontal sinus in acute sinusitis attacks discussing in the light of literature.
\end{abstract}

Keywords: Periorbital cellulitis; frontal sinus defect; acute sinusitis 
Geliş tarihi/Received: 04 Eylül 2014; Kabul tarihi/Accepted: 07 Aralık 2014

\section{*İletişim adresi:}

Dr. Onur Erdoğan, Kulak Burun Boğaz Anabilim Dalı, Dumlupınar Üniversitesi Tıp Fakültesi, TR-43000 Kütahya. E-posta: onurerdogan38@gmail.com

\section{Giriş}

Periorbital şişliğe, travma, böcek ısırığı, blefarit gibi birçok neden sebep olsa da; en sık nedenlerinden biri sinüzittir. Sinüzit, klinik olarak nazal kaviteyi ve paranazal sinüsleri döşeyen mukozaların, buradaki sıvıların ve/veya alttaki kemiğin ortaya koyduğu enflamatuar cevap olarak tanımlanabilir [1]. Sinüzitin, genellikle riniti takiben ortaya çıkması veya rinit ile birlikte bulunması, sinüslerin ve burun mukozasının histopatolojik olarak devamlılık göstermesi rinosinüzit şeklinde anılmasına sebep olmuştur. Sinüzit olgularında antibiyoterapinin yaygın olarak kullanılmasına rağmen hala bir takım komplikasyon görülebilmektedir [2]. Enfeksiyonun orbita ve intrakraniyal dokulara hizla yayılmasıyla çok ciddi ve mortalite riski yüksek komplikasyonlar ortaya çıkabilmektedir. Rinosinüzitli hastalarda \%3 oranında orbital komplikasyon ortaya çıkmaktadır [3]. Sinüzite bağlı orbital komplikasyonlar; periorbital sellülit, orbital sellülit, orbital apse, subperiosteal apse ve kavernöz sinüs trombozudur [2, 4-6]. Periorbital selülit daha çok çocukluk döneminde ve etmoid sinüslerin enflamasyonunda ortaya çıkan göz kapağında ödem, hiperemi, oküler ağrının olduğu fakat görmenin etkilenmediği, nadirende apsenin eşlik ettiği bir durumdur [6]. Bizim olgumuz frontal sinüsteki defektten kaynaklanan periorbital selüliti mevcuttu. Bu hali ile farklılık gösteren olgumuzu literatür eşliğinde tartışarak sunuyoruz.

\section{Olgu sunumu}

Sağ göz çevresinde şişlik ve ağrı şikayeti ile kliniğimize yönlendirilen erişkin erkek hastanın, anamnezinde üç yıl önce fonksiyonel endoskopik sinüs cerrahisi (FESC) olduğu, travma öyküsünün olmadığı tespit edildi. Hastamızda periorbital selilüte neden olan durumun akut sinüzit seyrinde frontal sinüs duvarındaki defekten meydana geldiği ve apse formasyonuna yol açtığını 'ince kesit paranazal sinüs bilgisayarlı tomografisi (BT) ile tespit edildi. Servise interne edilen hastaya, parenteral antibiyoterapi başlandi. Hastanın periorbital selilülit seyrinde olan absesi eksternal yaklaşımla drene edildi. Hastanın klinik tablosunun tedavinin 5. gününde düzeldiği görüldü. Operasyona alınan hastaya yapılan frontoetmoidal medial orbitotomi (Lynch) insizyonu sonrası frontal sinüs ön duvarındaki defektinin yaklaşık 2-3 mm çapında olduğu görüldü ve bonecement ile onarıldı. Post operatif 6 ay takip edilen hastanın izleminde periorbital selilüt izlenmedi.

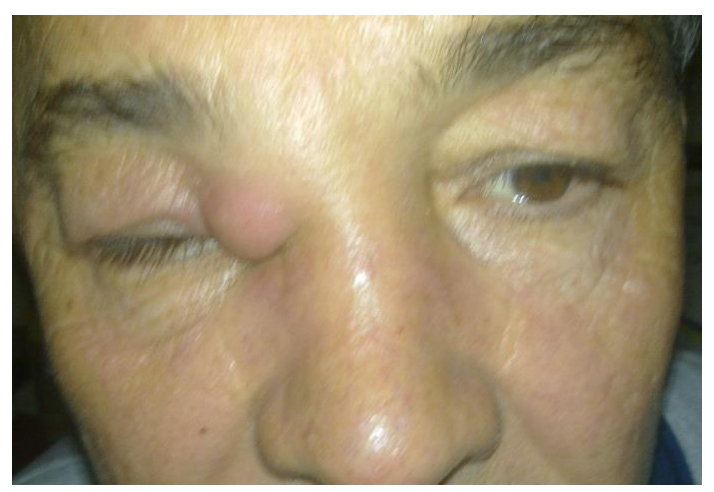

Resim 1. Periorbital selilüt. 


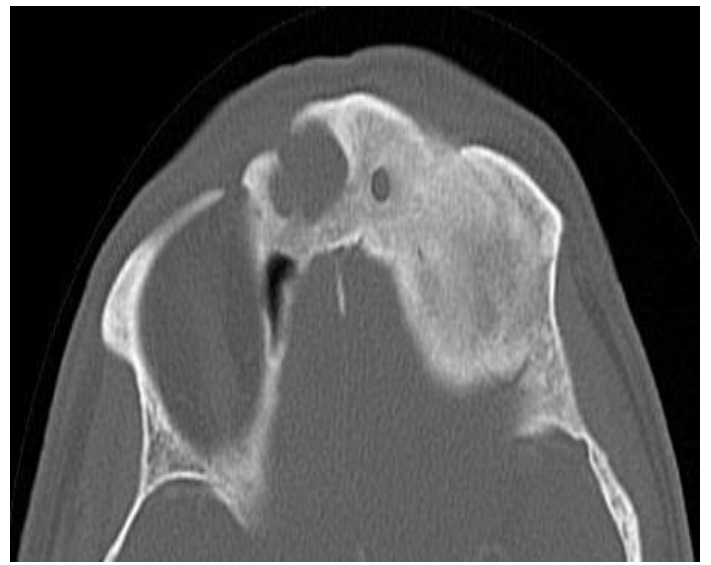

Resim 2. Paranazal BT aksiyal kesit.

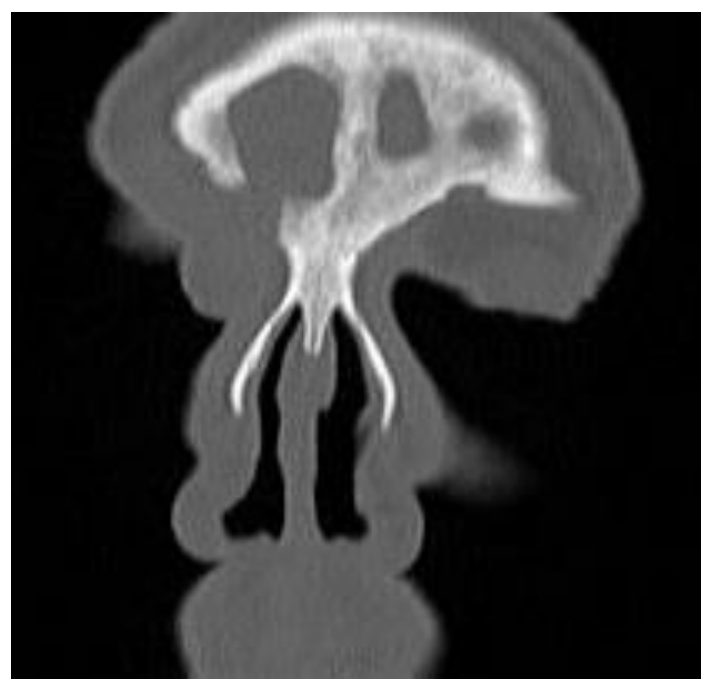

Resim 3. Paranazal BT koronal kesit.

\section{Tartışma}

Rinosinüzitli hastalarda \%3 oranında orbital komplikasyon ortaya çıkmaktadır [3]. Sinüzite bağlı orbital komplikasyonlar Chandler'ın tarifine göre periorbital sellülit, orbital sellülit, orbital apse, subperiosteal apse ve kavernöz sinüs trombozudur [7]. Periorbital selülit daha çok çocukluk döneminde ve etmoid sinüslerin enflamasyonunda ortaya çıkan göz kapağında ödem, hiperemi, oküler ağrının olduğu fakat görmenin etkilenmediği, nadirende apsenin eşlik ettiği bir durumdur [6]. Rinosinüzitin orbital komplikasyonları çok sayıda kan damarı ve sinirin katettiği ince iç duvarından gecerek orbitaya ulaşması neticesinde oluşmaktadır [8]. Özellikle çocuklarda etmoidal sinuzitte anatomik yakınlığından dolayı, enfeksiyoz materyal lamina papriseadan ve etmoidal hava boşluklarından kolaylıkla subperiorbital alana yayılabilmektedir [9]. Yüz ve lakrimal kese gibi periorbital dokulardaki enfeksiyonlardan lokal yayılımla, hematojen yolla, travma ya da cerrahi ile direk inokulasyonla ve dental enfeksiyonların sonucunda da periorbital selülit gelişebilir. Fakat bizim olgumuz litaretürde bilinenden farklı olarak erişkin bir hastada görülmekte ve etmoid sinüslerdeki infeksiyona sekonder değil frontal sinüsteki infeksiyonun frontal sinüs anterior duvarındaki defektten yayılımına bağlı ortaya çıkmaktayd 1

Frontal sinüs duvarındaki defektler mukopyosel, travma ya da iatrojenik sebeplere bağlı olabilmektedir. Hastamızın FESC öyküsünün bulunması her ne kadar bunun iatrojenik bir 
defekt olduğunu destekliyor olsa da, bu durumun kesin tanıs1 yapılamamaktadır. Hastadan ayrıntılı anamnez alıp, travma öyküsünü sorguladığımızda ise hastanın travma öyküsü bulunmamaktaydı. Hastanın ince kesit paranazal BT sinde de mukopyosel düşündürecek bir bulgu izlenmemekteydi.

Radyolojik görüntüleme yöntemleri hem tanının doğrulanması hem de paranazal sinüslere veya sinüzit komplikasyonlarına yönelik cerrahi tedavinin planlanmasında önemlidir [2]. BT, paranazal enfeksiyonların, kemik defektlerin ve komplikasyonların değerlendirilmesinde oldukça etkin bir görüntüleme yöntemidir. Magnetik rezonans (MR) görüntülemede ise kavernöz sinüs trombozu gibi sinüs enfeksiyonlarına bağl1 komplikasyonların değerlendirilmesinde önemlidir. Hastanın FESC öyküsü olması ve orbital komplikasyon gelişmesi paranazal sinüs BT için gereklilik oluşturdu. Yapılan paranazal sinüs BT incelemesinde frontal sinüs anterior duvarındaki defekt ve buna bağlı olarak oluşan periorbital selilütin kesin tanısı konuldu.

Komplike olmamış vakalarda erken tanı ve tedavi komplikasyonları önlemede önemlidir [10]. Komplikasyon geliştiğinde ise medikal tedavi yeterli olmayacak cerrahi tedaviler gündeme gelecektir. Sinüzit seyrinde periorbital selilüt komplikasyonu gelişen hastaların tedavisinde genel görüş enfekte sinüslerin drenajı ve periorbital selilüt sırasında oluşan absenin drenaj1 ve beraberinde medikal tedavidir [11, 12]. Cerrahi tedavide endoskopik sinüs cerrahisi kullanılabileciği gibi klasik eksternal yaklaşımlarda tercih edilmektedir. Migirov ve ark. [13] yaptıkları çalışmada endoskopik sinus cerrahisini önermektedirler. Günümüzde cerrahi gerektiren frontal sinüs hastalıklarının çoğu endonazal yaklaşımlarla başarılı bir şekilde tedavi edilmektedir. Bunun yanında kemik defekti bulunan ve ya patolojiye hakim olunamayan olgularda açık cerrahi yaklaşım gereklidir [14]. Bundan dolayı biz de hem patolojiye daha iyi hakim olacağımızı düşündügümüzden hem de kemik defekt onarımının daha kolay olacağını düşündüğümüzden dolayı açık cerrahiyi tercih ettik.

Sonuç olarak; sinüzit atağında orbital komplikasyonlar izlenebilmektedir. Fakat sık görülenin aksine orbital komplikasyonlar sadece etmoid sinüzite bağlı olarak değil, frontal sinüse bağl enfeksiyonlara sekonder de ortaya çıkabileceği göz önünde bulundurulmalıdır. Detaylı bir anamnez ve görüntüleme yöntemleri frontal sinüsteki defekti tespit edip tedavinin planlanması açısından yol göstericidir.

\section{Kaynaklar}

1. Lanza DC, Kennedy DW. Adult Rhinosinusitis defined. Otolaryngol-Head and Neck Surg 1997; 3: 107.

2. Wolf SR, Göde U, Hosemann W. Endonasal endoscopic surgery for rhinogen intraorbital abscess: A report of six cases. Laryngoscope 1996; 106: 105-10.

3. Oliverio PJ, Benson ML, Zinreich SJ. Update on imaging for functional endoscopic sinus surgery. Otolaryngol Clin North Am 1995; 28: 585-608.

4. Önerci M, Haberal İ. Sinüzit. Çelik O. Kulak Burun Boğaz Hastalıkları ve Baş Boyun Cerrahisi. İstanbul: Turgut Yayıncılık 2002; 411-33.

5. Watkins LM, Pasternack MS, Banks M, Kousoubris P, Rubin PAD. Bilateral Cavernous Sinus Thromboses and Intraorbital Abscesses Secondary to Streptococcus milleri. Ophthalmology 2003; 110: 569-74.

6. Hytonen M, Atula T, Pitkaranta A. Complications of Acute Sinusitis in Children. Acta Otolaryngol Suppl 2000; 543: 154-7.

7. Chandler JR, Langenbrunner DJ, Stevens ER. The pathogenesis of orbital complications in acute sinusitis. Laryngoscope 1970; 80: 1414-28.

8. Domville-Lewis C, Friedland PL, Santa Maria PL. Pott's puffy tumour and intracranial complications of frontal sinusitis in pregnancy. J Laryngol Otol 2013; 127: $35-8$.

9. Jones H, Trinidade A, Jaberoo MC, Lyons M. Periorbital cellulitis, subgaleal abscess and superior sagittal sinus thrombosis: A rare combination of 
complications arising from unilateral frontal sinusitis. J Laryngol Otol 2012; 126 : 1281-3.

10. Allan K, Atkinson H, Agada F. Posterior orbital cellulitis: Case report and literature review. J Laryngol Otol 2013; 127: 1148-51.

11. Johnson JT, Infections. In: Krause CJ. Otolaryngology-Head and Neck Surgery, Second Edition. Mosby Year Book 1993: 929-40.

12. Younis RT, Lazar RH, Bustillo A, Anand VK. Orbital infection as a complication of sinusitis are diagnostic and treatment trends changing? Ear Nose Throat $\mathrm{J}$ 2002; 81: 771-5.

13. Migirov L, Yakirevitch A, Bedrin L, Wolf M. Endoscopic sinus surgery for medial orbital subperiosteal abscess in children. J Otolaryngol Head Neck Surg 2009; 38: 504-8.

14. Weber R, Draf W, Keerl R. Osteoplastic frontal sinus surgery with fat obliteration: Technique and long-term results using magnetic resonance imaging in 82 operations. Laryngoscope 2000; 110: 1037-44. 